\title{
Algunos rasgos de la delincuencia en España a comienzos del siglo XXI
}

\author{
José Luis Díez Ripollés \\ Universidad de Málaga.
}

\begin{abstract}
RESUMEN
En un momento en que las decisiones político-criminales en España han pasado a tener una relevancia social, mediática y política hasta hace poco desconocida, este trabajo pretende poner de relieve, sirviéndose casi en exclusiva de gráficos estadísticos, cual es la realidad de la delincuencia en España al comienzo del siglo XXI. El objetivo es evitar visiones estereotipadas de la criminalidad española.

Palabras clave: estadística criminal, evolución de la criminalidad, política criminal
\end{abstract}

\begin{abstract}
Considering the unprecedented media coverage and social and political salience given to criminal justice issues in Spain, this paper intends to describe -almost exclusively through statistical charts- the Spanish crime situation at the beginning of this century. The main aim is to confront the dominant stereotypical presentation of Spanish criminality.

Keywords: crime statistics, crime trends, criminal justice policy

Fecha de recepción: 24-11-2006

Fecha de aceptación: 26-01-2006
\end{abstract}

\section{Introducción.}

Este trabajo tiene una pretensión modesta. Aspira únicamente a recordar, sirviéndose casi en exclusiva del uso de gráficos, cual es en términos generales la realidad de la delincuencia en España en unos momentos, al inicio del nuevo siglo, en los que las decisiones políticocriminales han pasado a tener una relevancia social, mediática y política hasta hace poco desconocida.

Lo que sigue no pretende ser un análisis minucioso y diferenciado de las diferentes variables que caracterizan la criminalidad española, sea por tipologías delictivas, sea por sujetos implicados, sea por cualquier otro criterio significativo. Recientemente han comenzado a aparecer informes monográficos que con una profundidad notable, y aprovechando la clara mejora y accesibilidad de ciertas estadísticas oficiales, se ocupan de sacar conclusiones trascendentes en el nivel nacional e incluso autonómico sobre la evolución de la delincuencia española en sus diferentes facetas ${ }^{1}$. Aspiro únicamente a poner de relieve unos pocos aspectos genéricos de nuestro presente delincuencial, en la medida en que son capaces de transmitir una visión general y contextualizada de la actual criminalidad española y que, además, suministran una perspectiva que no se compadece bien con prejuicios muy asentados en la actual discusión politicocriminal.

\footnotetext{
${ }^{1}$ Los más comprensivos son, sin duda, los informes del Observatorio de la delincuencia en Andalucía (ODA), que analizan desde 2003 la situación penal y penitenciaria nacional y autonómica andaluza desde muy diversos aspectos. Véanse García España y Pérez Jiménez. "Evolución de la delincuencia en España y Andalucía: Análisis e interpretación de las estadísticas oficiales". Informe ODA 2004. Fundación El Monte-Instituto andaluz ínteruniversitario de Criminología eds. Málaga. 2004; de las mismas. "Seguridad ciudadana y actuaciones policiales". Informe ODA 2005. Fundación El Monte-Instituto andaluz ínteruniversitario de Criminología eds. Málaga. 2005.
}

Revista Española de Investigación Criminológica

Artículo 1, Número 4 (2006) http://www.criminologia.net

ISSN 1696-9219 
En la mayor parte de los casos las informaciones utilizadas se basan en datos de las estadísticas policiales, cuya mayor fiabilidad frente a las judiciales y del ministerio físcal goza de reconocida aceptación en los círculos criminológicos ${ }^{2}$.

\section{Comparación de la criminalidad europea y española.}

La progresiva relevancia política y mediática que los temas de criminalidad han adquirido en los últimos años en España se justifica con frecuencia en la asunción de que nuestro país se ha convertido en uno de los países europeos occidentales con mayores problemas de seguridad ciudadana. Tales creencias van con frecuencia acompañadas de referencias al elevado número de comportamientos violentos registrados en nuestra sociedad.

Si acudimos a la última edición del European Sourcebook of Crime and Criminal Justice Statistics, que recoge datos hasta el año 2000 de la práctica totalidad de los países integrados en el Consejo de Europa ${ }^{3}$, observamos que nuestro país posee unas tasas de criminalidad por cada 100.000 habitantes claramente por debajo de la media europea. Más en concreto, es el último de los grandes países de la Unión europea Alemania, Francia, Reino Unido, Italia, España, Polonia- en nivel de criminalidad. Ello se puede ver en el gráfico 1.

\section{Gráfico 1.}

\section{Tasa de criminalidad comparada Europa/España.} Año 2000. x 100.000 hs.

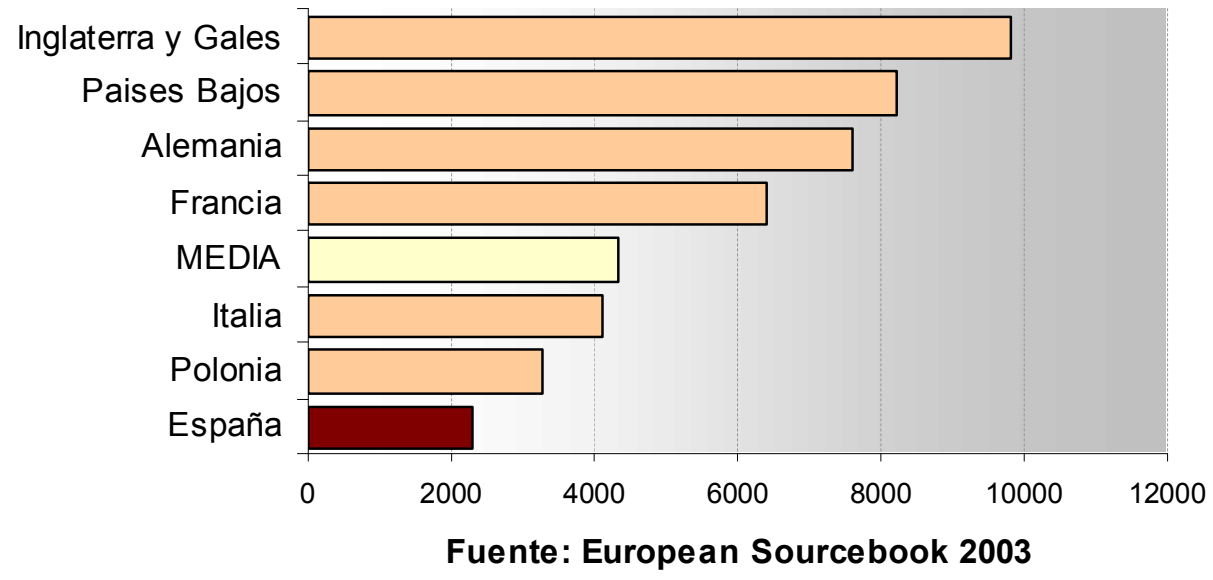

Esa posición a la cola de los grandes países europeos se mantiene e incluso acentúa si nos referimos al delito por antonomasia, el homicidio y sus clases. Si los grandes de la Unión europea ya se encuentran por debajo de la media del conjunto de

\footnotetext{
${ }^{2}$ Véase un análisis de las razones que convierten en menos fiables las estadísticas judiciales y de la fiscalía, sin perjuicio de reconocer cierta mejora que se ha producido en los últimos tiempos en las primeras, en Stangeland -García España -Márquez. "Discrepancias entre estadísticas policiales y judiciales". Boletín criminológico. $\mathrm{n}^{\circ}$ 2. julio-agosto. 1994; Domínguez Martínez y otros. "Estadísticas sobre la delincuencia en Andalucía". Instituto estadístico de Andalucía. 2000.

${ }^{3}$ Vease European Sourcebook of Crime and Criminal Justice Statistics. $2^{\text {nd }}$ edition. WODC. 2003, el cual está basado en datos policiales. No pueden pasarse por alto los problemas metodológicos que se plantean al intentar comparar tan alto número de países, en especial debido a la diversidad de contenidos de infracciones con una misma denominación, como los autores del estudio se ocupan de recordar -págs. 1628-, pero estamos en cualquier caso ante el intento más riguroso de comparación entre todos los países europeos.
} 
países del Consejo de Europa -consecuencia de las elevadas tasas existentes en Europa oriental-, España sigue manteniéndose al fondo de esa clasificación, como se aprecia en el gráfico 2.

Gráfico 2.

Tasa de homicidios consumados Europa/España. Año 2000. x 100.000 hs.

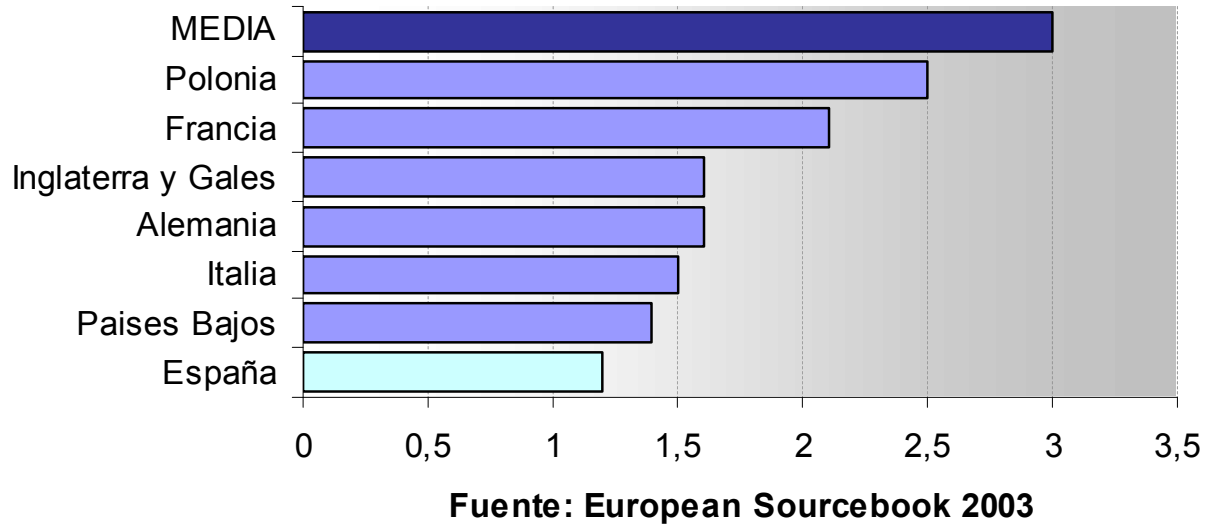

Algo parecido sucede, en este caso delante de Italia, con uno de los delitos que suscita mayor intranquilidad entre la población, las violaciones, a juzgar por gráfico 3.

\section{Gráfico 3.}

\section{Tasa de violaciones Europa/España. Año 2000. x 100.000 hs.}

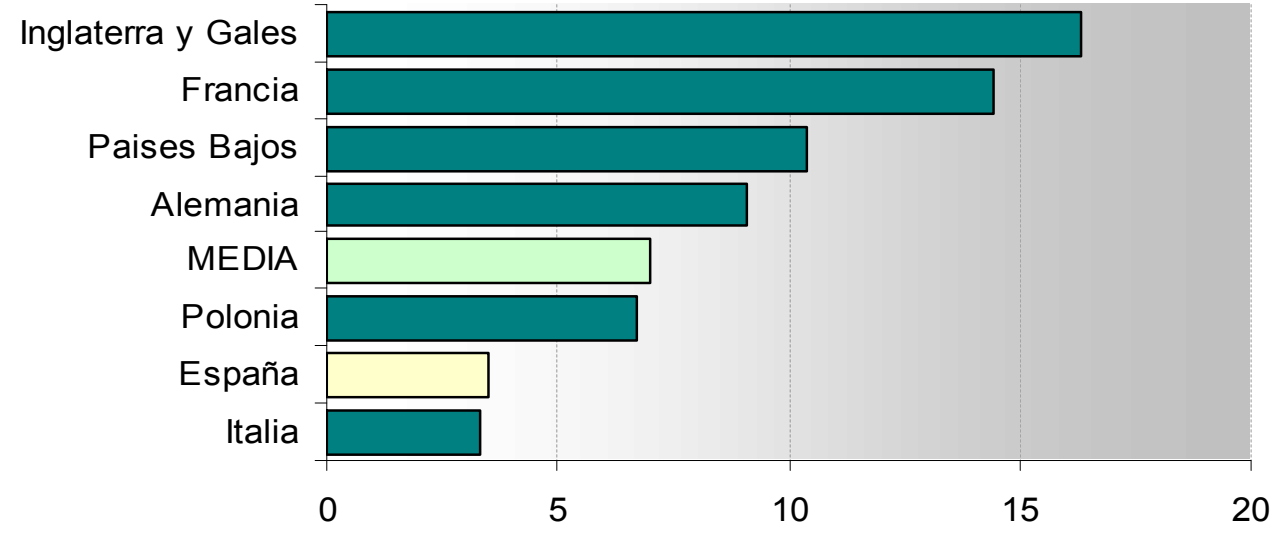

Fuente: European Sourcebook 2003

Las cosas cambian drásticamente cuando entramos en el ámbito de los delitos patrimoniales, algo que ya es conocido desde hace tiempo. En efecto, nuestro país ha mantenido tradicionalmente unas altas tasas de delitos contra el patrimonio, que no solo se reflejan en el elevado porcentaje que corresponde a estos delitos en la estructura de la criminalidad española, sino que coloca a nuestro país a la cabeza de los grandes países de Europa occidental -aunque no demasiado lejos de Francia o Inglaterra- y muy por encima de la media de toda Europa. Baste, para confirmar un hecho bien conocido, con 
las cifras sobre robos con violencia, la conducta quizás más inquietante, recogidas en el gráfico $4^{4}$.

\section{Gráfico 4.}

\section{Tasa de robos con violencia Europa/España.}

Año 2000. x 100.000 hs.

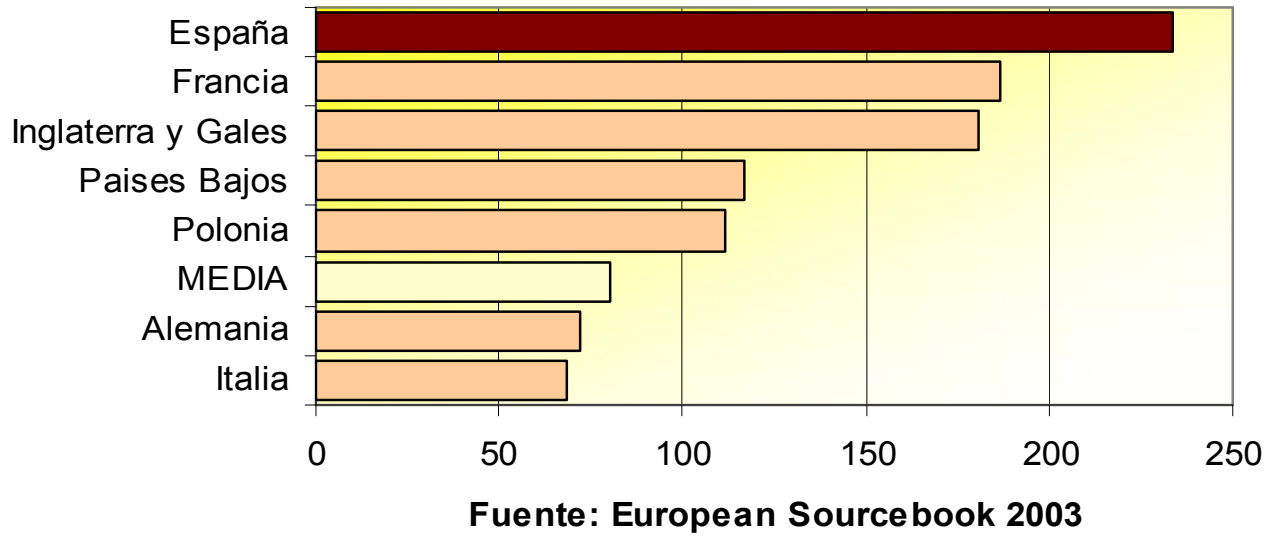

Sin embargo, un tipo de conductas que en nuestra sociedad parece aceptado que se produce con mucha frecuencia, el tráfico de drogas, no es tan alarmante en términos comparativos como pudiera pensarse: Sin duda estamos en la parte alta de los países de la Unión europea, aunque superados por algún país importante como Inglaterra o cercano como Portugal, pero la actual realidad de Europa oriental nos hace situarnos claramente por debajo de la media europea, a tenor de lo recogido en el gráfico $5^{5}$.

\section{Gráfico 5.}

\section{Tasa de tráfico de drogas Europa/España. Año 2000.x 100.000 hs.}

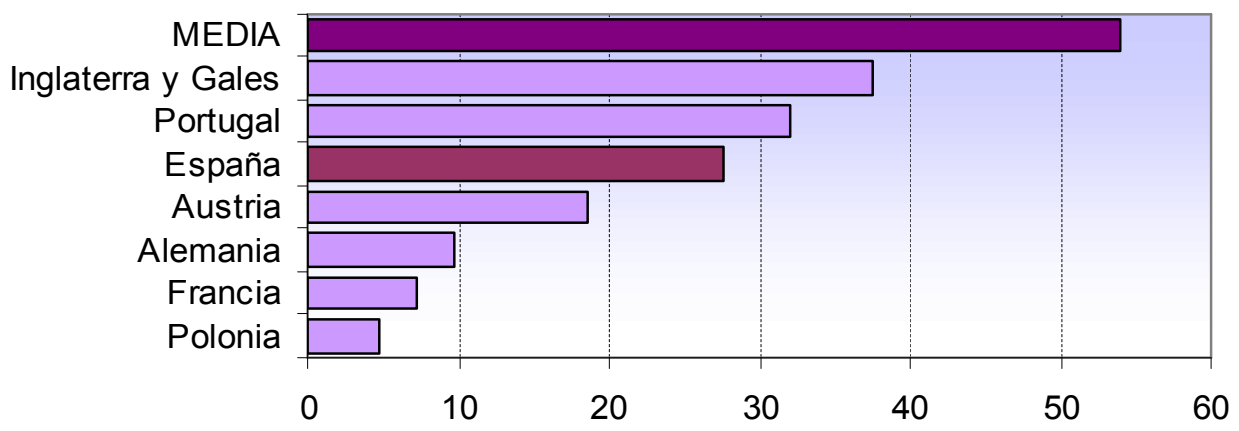

Fuente: European Sourcebook 2003

\footnotetext{
${ }^{4} \mathrm{He}$ renunciado a incluir cifras sobre hurtos o robos con fuerza debido a que presentan ciertos problemas metodológicos que lastran una fiable comparación. En todo caso, las disponibles no dan números tan relativamente altos para España como las de robo con violencia.

${ }^{5}$ No hay datos de Italia y Países Bajos del año 2000 en el European Sourcebook.
} 
La conclusión de esta breve panorámica nos conduce a lo dicho al principio de este apartado: De acuerdo a los últimos datos comparados disponibles, no es correcto afirmar que vivamos en un país con una delincuencia elevada, más bien procede la afirmación contraria, estamos ante uno de los países europeos con menores tasas de criminalidad en general, y violenta - con la salvedad de los robos violentos- en particular.

\section{La estructura de la criminalidad española y su percepción social.}

Si nos concentramos ahora en la evolución y estructura de la criminalidad española, y aprovechamos asimismo para confrontar tales datos con las percepciones sociales, obtenemos resultados igualmente ilustrativos.

La tasa de criminalidad española, medida en infracciones por cada 1000 habitantes, registró un incremento fuerte y sostenido a lo largo de casi toda la década de los 80 del pasado siglo, manteniéndose estable hasta mediados de los años 90. A partir de ese momento inicia un paulatino incremento, que se ha visto algo frenado en los dos últimos años, como muestra el Gráfico $6^{6}$.

\section{Gráfico 6.}

\section{Evolución de la tasa de criminalidad española.}

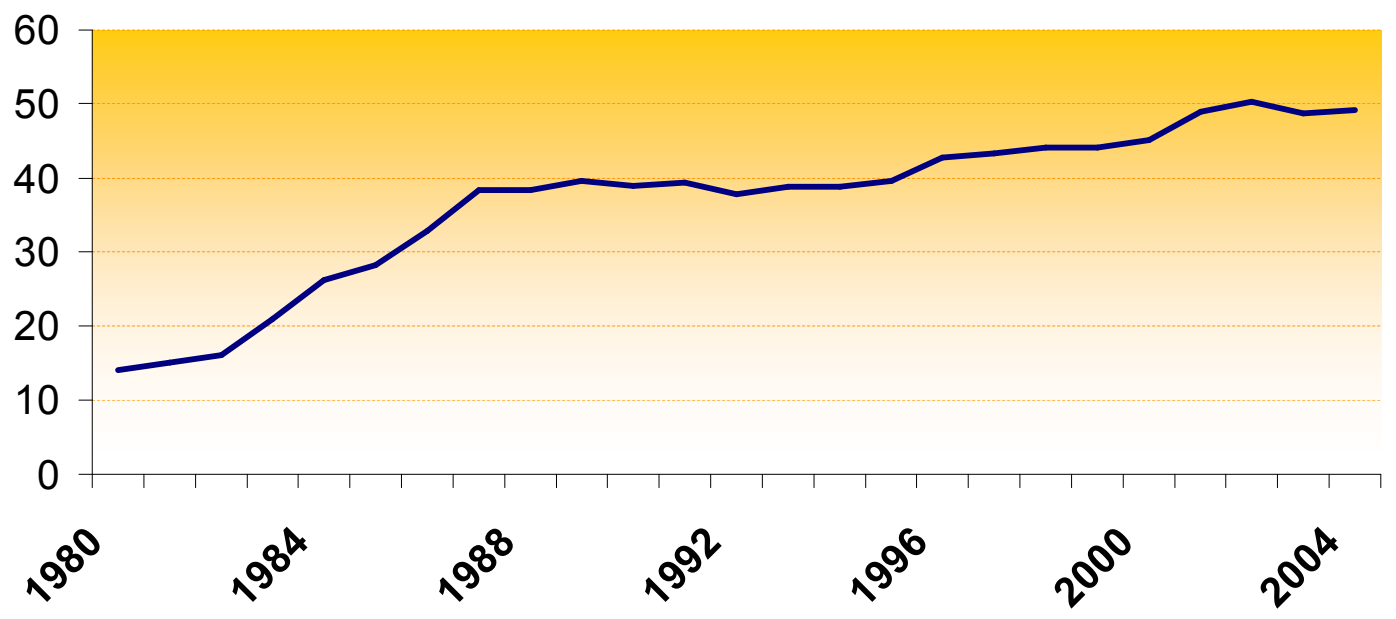

Fuente: García España/Pérez Jiménez. Informe ODA 2005.

Especialmente interesantes son los datos que se derivan de trazar de forma diferenciada la evolución en cifras absolutas de los delitos y de las faltas conocidos en todos estos años, como hacemos en el gráfico 7: Así, tras el incremento de los años 80, los delitos tienden a descender y luego a mantenerse estables durante los años 90, pasando luego por un cuatrienio de inestabilidad con repuntes en ambos sentidos. Por el contrario, las faltas mantienen un pronunciado y prácticamente ininterrumpido ascenso durante todo este periodo. Es más, desde el año 2002 el número de faltas ha superado al

\footnotetext{
${ }^{6}$ Debe hacerse notar que tanto en este Gráfico como en el siguiente desde el año 2000 se han complementado los datos procedentes del Ministerio del Interior con los provenientes de los Mozos de escuadra.
}

Revista Española de Investigación Criminológica

Artículo 1, Número 4 (2006) http://www.criminologia.net 
de delitos, lo que ni siquiera se ha visto perturbado por las recientes reformas que, con motivo de la persecución de la violencia doméstica, han trasladado al Libro II del código penal conductas antes incluidas en el Libro III.

\section{Gráfico 7.}

\section{Evolución de delitos y faltas. 1980-2004.}

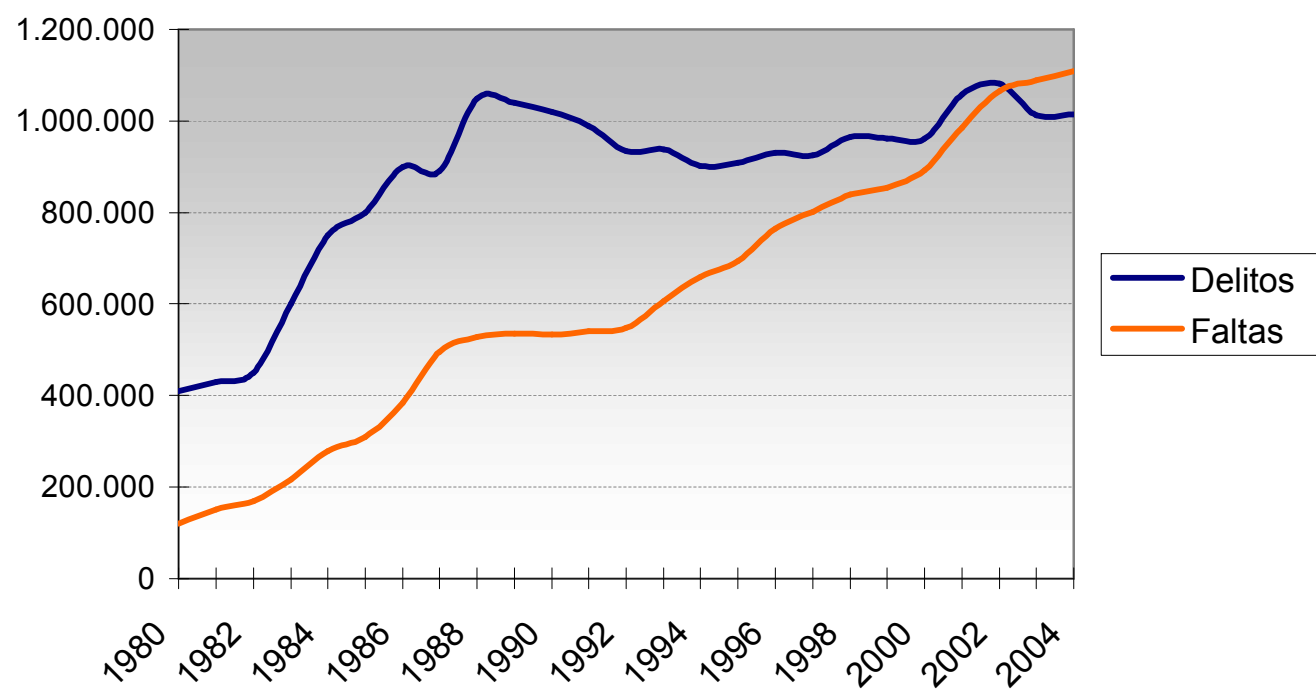

Fuente: García España. RDPyC. $n^{\circ} 16$.

La criminalidad española no ha variado, por lo demás, su estructura desde hace muchos años. Los hurtos y robos dan cuenta de la gran mayoría de las infracciones -en torno al $70 \%$ del conjunto de delitos-, quedando el resto de delitos, patrimoniales o no, a una gran distancia. Eso reza igualmente para los delitos relativos a drogas o los delitos contra las personas, como expresa el gráfico 8 .

\section{Gráfico 8.}

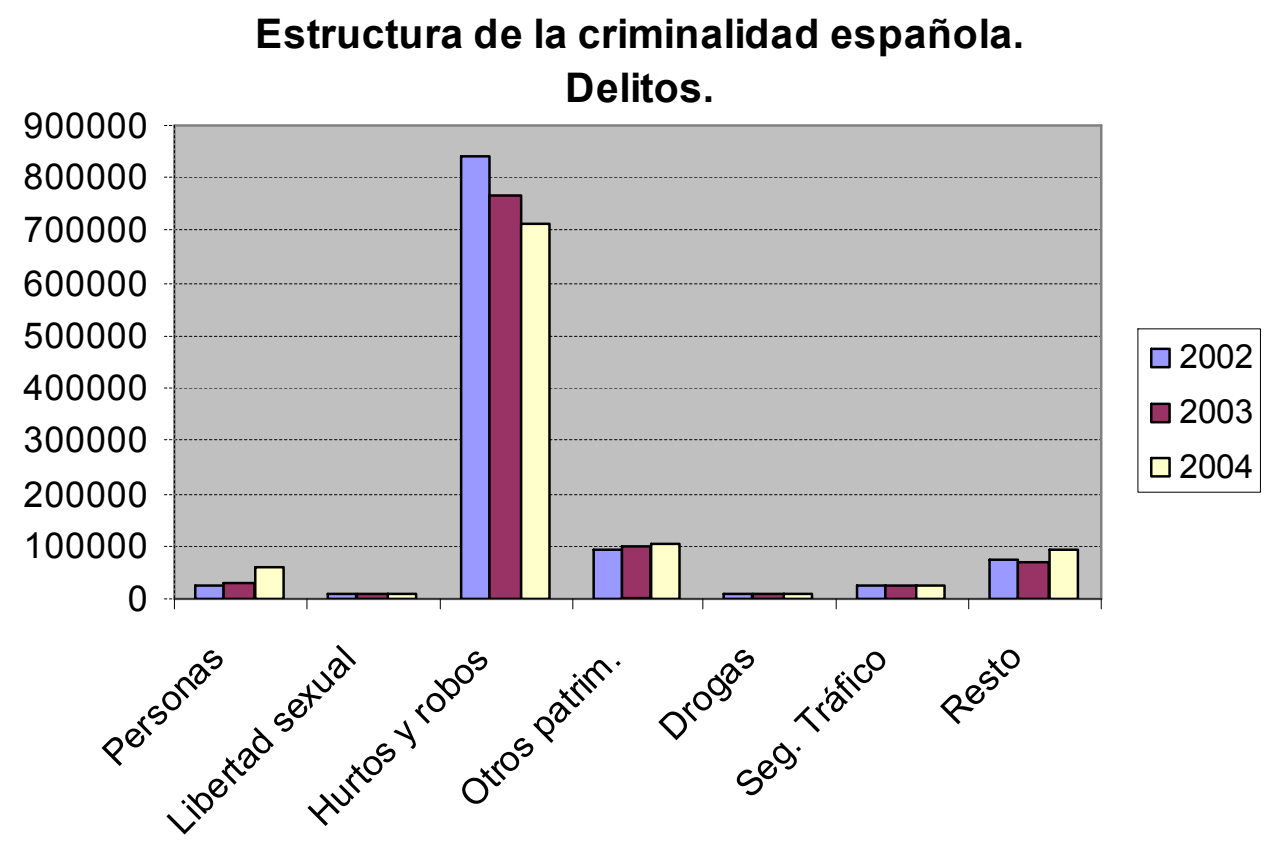

Fuente: Elaboración propia a partir de datos oficiales.

Revista Española de Investigación Criminológica

Artículo 1, Número 4 (2006) http://www.criminologia.net 
Dentro de ese bajo nivel de comisión de los delitos contra las personas, las recientes reformas de 2003 han originado un sustancial incremento de los delitos de malos tratos, que han pasado a constituir casi el $70 \%$ de esos delitos contra las personas. Por el contrario, las lesiones presentan un crecimiento muy moderado, y los homicidios, donde son amplia mayoría los intentados, se mantienen estables, con tendencia más bien a la baja. En cualquier caso, ese crecimiento de los delitos de malos tratos ha hecho que el conjunto de delitos contra las personas haya pasado de representar poco más del $2 \%$ de todos los delitos en el año 2000 a estar a punto de alcanzar el 6\% en 2004. Ello se percibe con claridad en el gráfico 9 .

\section{Gráfico 9. \\ Estructura de la criminalidad de los delitos contra las personas. 2004.}

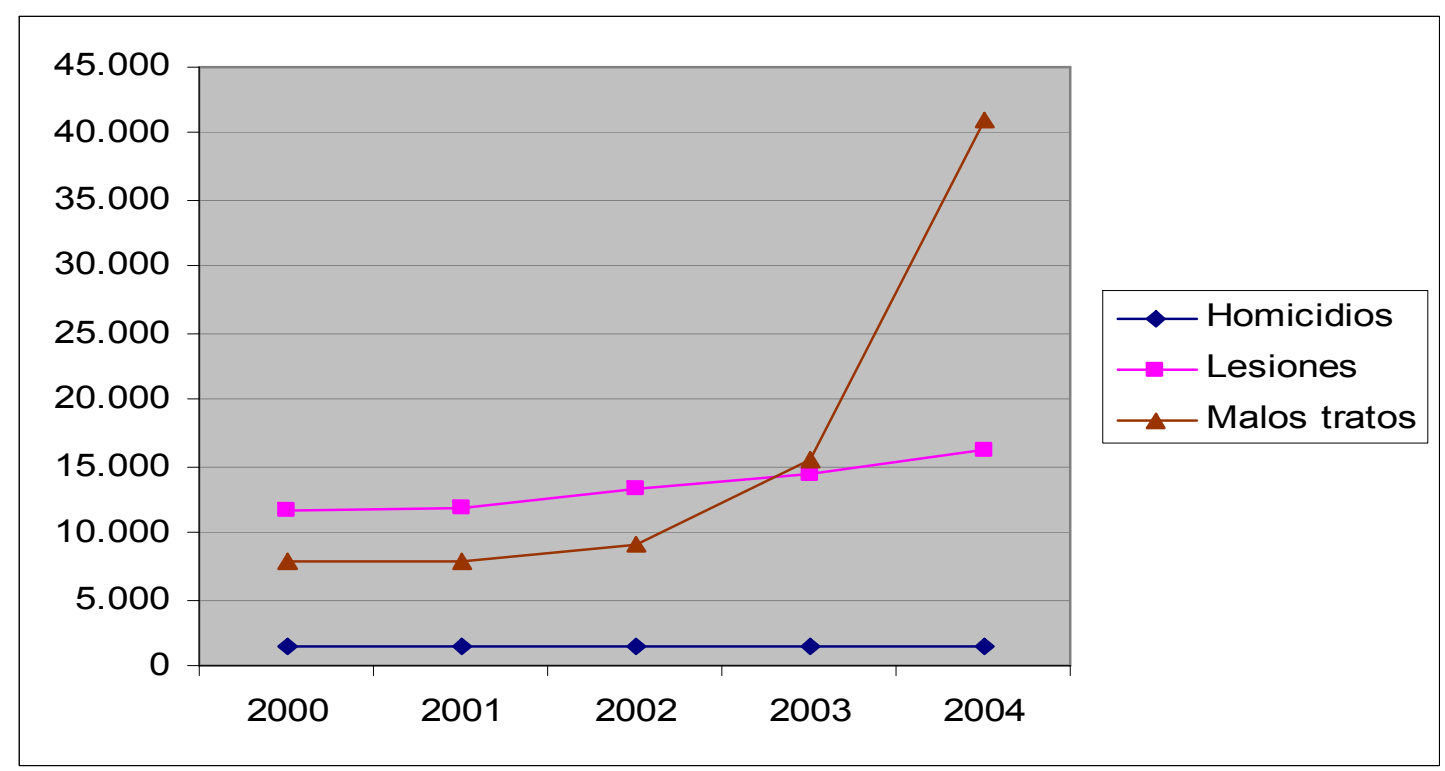

Fuente: García España/Pérez Jiménez. Informe ODA 2005.

No viene mal recordar, en todo caso, que la evolución de la tasa de criminalidad no se corresponde con el discurrir de las percepciones sociales. Los siguientes gráficos 10 y 11 muestran, tras realizar algunos ajustes para facilitar la comparación ${ }^{7}$, esas dinámicas diversas.

Así, el primero de ellos nos muestra cómo, a unas tasas de criminalidad en el

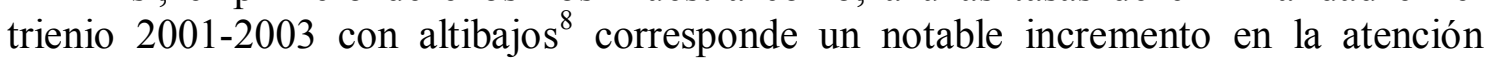
mediática a los asuntos relacionados con la delincuencia, y un persistente aumento en la preocupación por el delito entre la opinión pública ${ }^{9}$.

\footnotetext{
${ }^{7}$ En el gráfico 10 los datos de hechos conocidos se han dividido por 10.000, la media mensual de noticias sobre delincuencia va referida al diario El País y el porcentaje de preocupación por el delito alude a la media anual de encuestados por el CIS que incluyeron la delincuencia entre los tres principales problemas de España. En todo caso el Gráfico, al comparar medidas heterogéneas, tiene valor solo en la medida en que permite registrar la discrepante evolución entre las tres variables aludidas.

${ }^{8}$ Véase con más precisión en Gráfico 6.

${ }^{9}$ Véase un análisis detenido de la influencia de los medios de comunicación en los sentimientos sociales de inseguridad, en Soto Navarro. "La influencia de los medios en la percepción social de la delincuencia". RECPC. 2005.
} 


\section{Gráfico 10. \\ Correspondencia entre tasa de criminalidad, atención mediática y preocupación por el delito.}

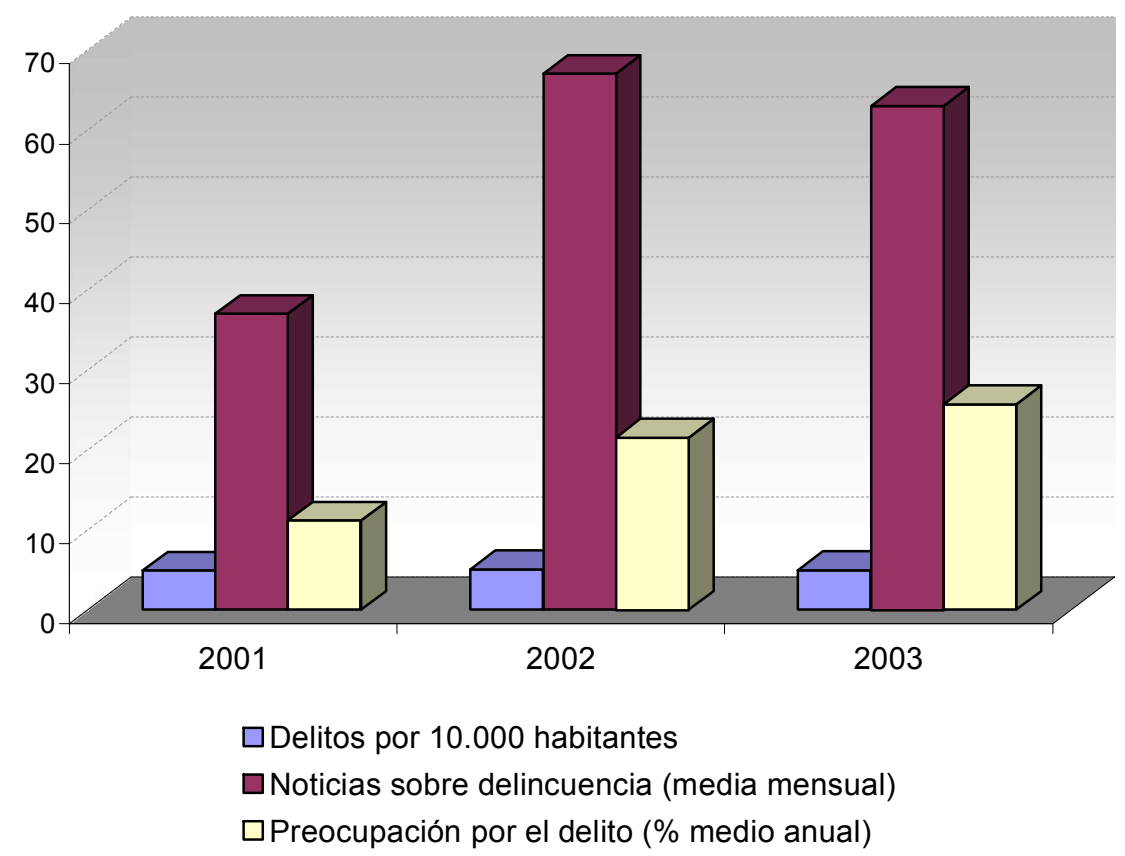

Fuente: Soto Navarro. RECPC. 2005

El segundo, por su lado, confronta la evolución de la tasa de criminalidad en el último cuatrienio con las desacompasadas oscilaciones de las percepciones sociales de preocupación y miedo por el delito ${ }^{10}$.

Gráfico 11.

Relación entre sentimiento de inseguridad y tasa de criminalidad. 2000-2004.

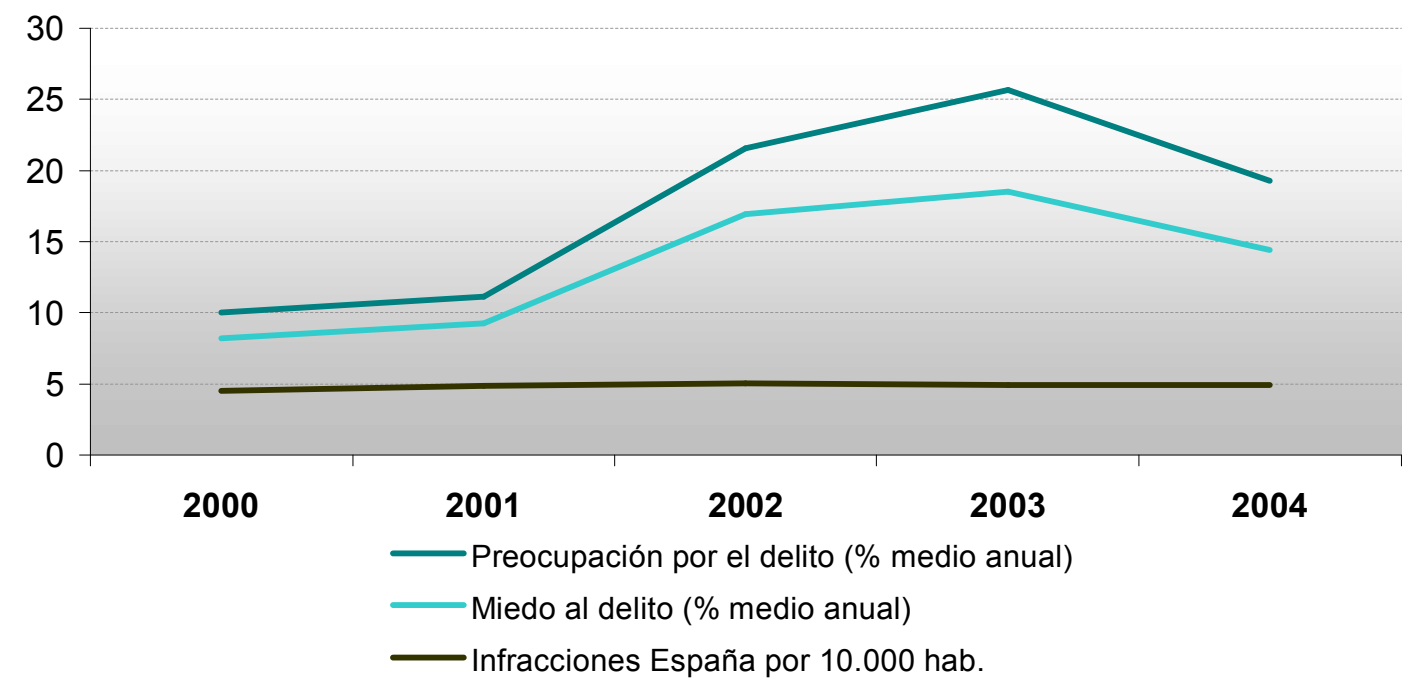

Fuente: García España/Pérez Jiménez. Informe ODA 2005.

\footnotetext{
${ }^{10}$ Véase la tasa de criminalidad con más precisión en Gráfico 6. Los datos de preocupación y miedo al delito proceden de las encuestas mensuales del CIS.
}

Revista Española de Investigación Criminológica

Artículo 1, Número 4 (2006) http://www.criminologia.net 


\section{El uso de la prisión en España.}

No parece haber dudas de que España en los últimos años está haciendo un uso excesivo de la prisión.

La primera referencia significativa procede de los datos del Consejo de Europa sobre el volumen de población penitenciaria en sus diferentes Estados miembros ${ }^{11}$. A fecha de 2003 nuestro país, pese a las bajas tasas de criminalidad que hemos visto muestra en el contexto europeo, ostenta unas tasas de encarcelamiento muy cercanas a la media del conjunto de Europa, media, por otra parte, que se eleva notablemente debido a la presencia de numerosos países de Europa oriental. Si comparamos las tasas españolas con las de los grandes países de la Unión europea, sólo Inglaterra/Gales y Polonia las superan, como se aprecia en gráfico 12.

\section{Gráfico 12.}

Tasa comparada de población reclusa por 100.000 hs. Año 2003

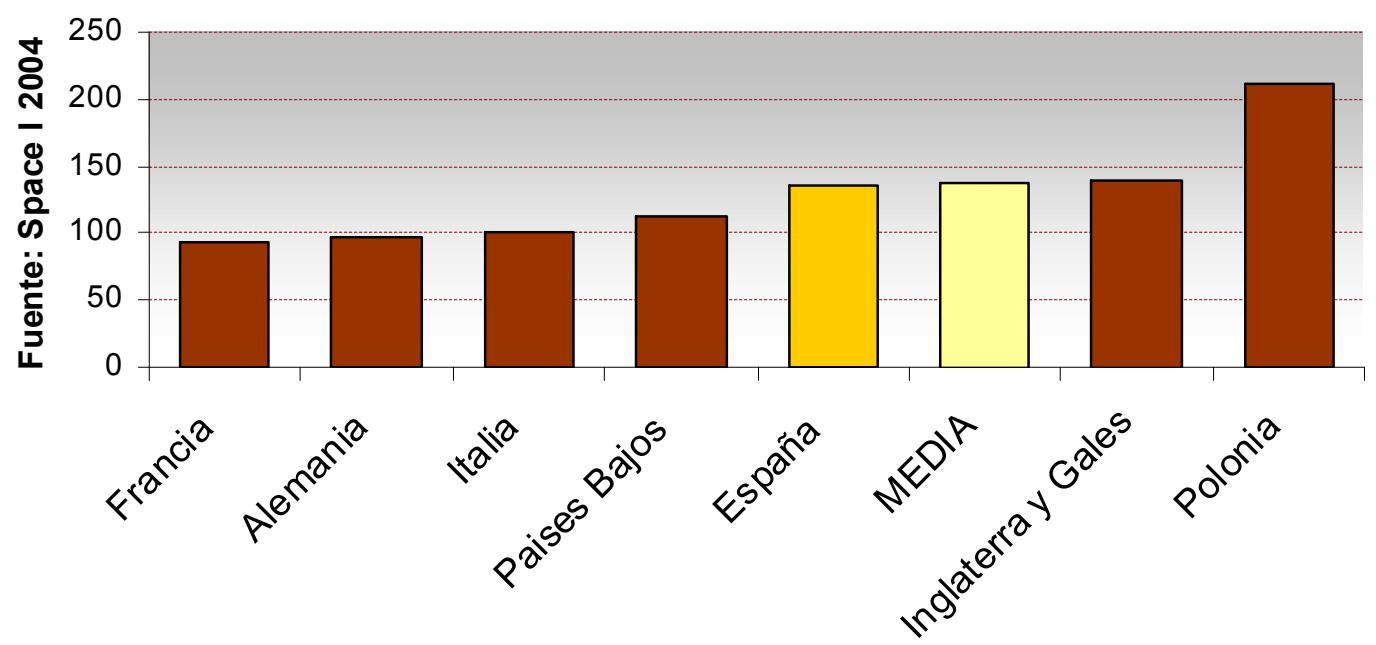

A su vez el gráfico 13 refleja con claridad cómo desde 1996 se ha producido un incremento incesante de la tasa de población penitenciaria en España, que se ha acelerado notablemente a partir de 2001.

${ }^{11}$ Véase Space I. Survey 2003. Council of Europe Penal Statistics. 2004.

Revista Española de Investigación Criminológica

Artículo 1, Número 4 (2006) http://www.criminologia.net 
Gráfico 13.

\section{Evolución de la población penitenciaria en España.}

Años 1992-2004.

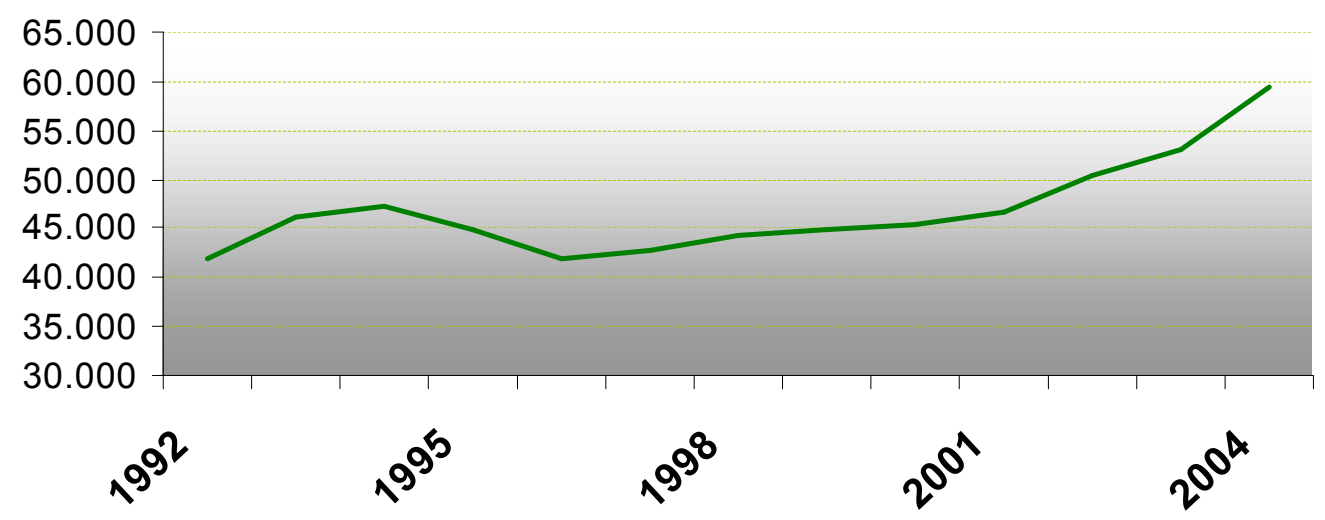

Fuente: García España/Pérez Jiménez. Informe ODA 2005.

Por lo demás, el siguiente gráfico 14 nos recuerda algo bien conocido desde hace tiempo: En 2004 más del 77\% de los penados se encuentran en prisión por la comisión de delitos patrimoniales, predominantemente hurtos y robos, o delitos relativos a drogas.

\section{Gráfico 14.}

Población penitenciaria penada por tipologías delictivas.

2004.

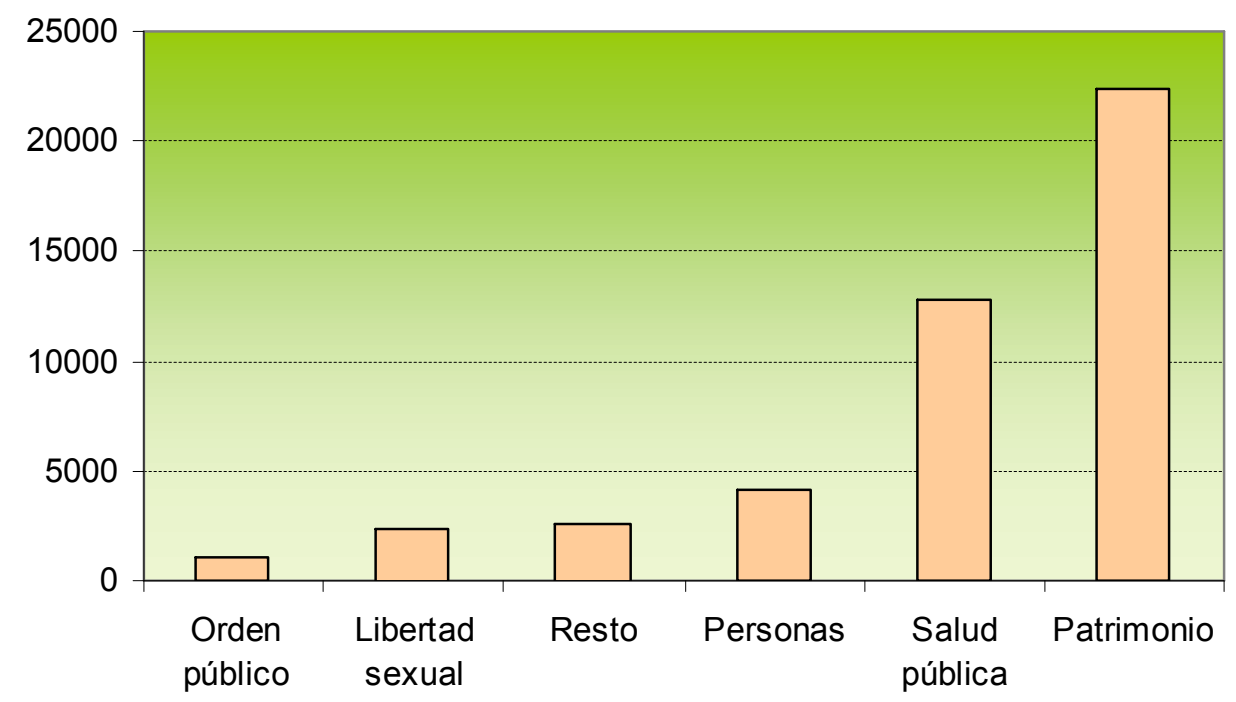

Fuente: Elaboración propia a partir de datos oficiales.

Una percepción visual de impacto nos la suministra el gráfico 15, en el que, tomando como base 0 el año 2000, se representan las evoluciones porcentuales del número de delitos conocidos, del número de detenciones llevadas a cabo, y de la población reclusa. 


\section{Gráfico 15.}

Evolución hechos conocidos, detenciones, población penitenciaria. Base año 2000.

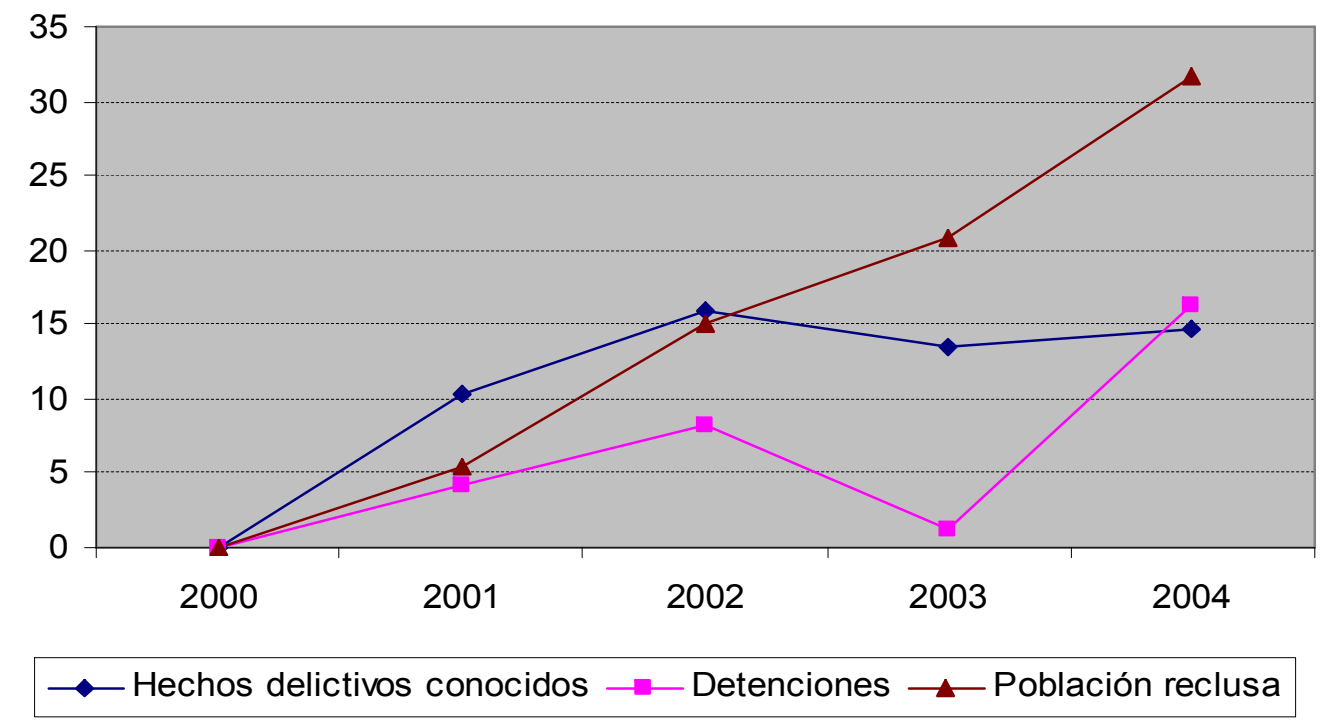

Fuente: Elaboración propia a partir de datos oficiales.

Se puede, pues, concluir que el sistema de penas español descansa de una manera exagerada en el empleo de la prisión, lo que transmite una imagen, cuando menos, anticuada de nuestra política criminal. No parece que España se haya incorporado al grupo de sociedades desarrolladas que, al margen de la intensidad punitiva que mantengan, se esfuerzan por diversificar su sistema de sanciones para evitar los costes de todo tipo que el abuso del encarcelamiento conlleva.

\section{La delincuencia de menores en España.}

$\mathrm{Si}$ atendemos a las infracciones más graves que pueden cometer los menores y que, por ello, justifican su detención por las fuerzas de seguridad, apreciamos en el gráfico 16 que tienen una tendencia más bien a la baja, sin que se hayan superado los niveles del año 2000 en los cuatro años siguientes, y mostrando los años 2003 y 2004 un sucesivo descenso. 


\section{Gráfico 16.}

\section{Detenciones de menores}

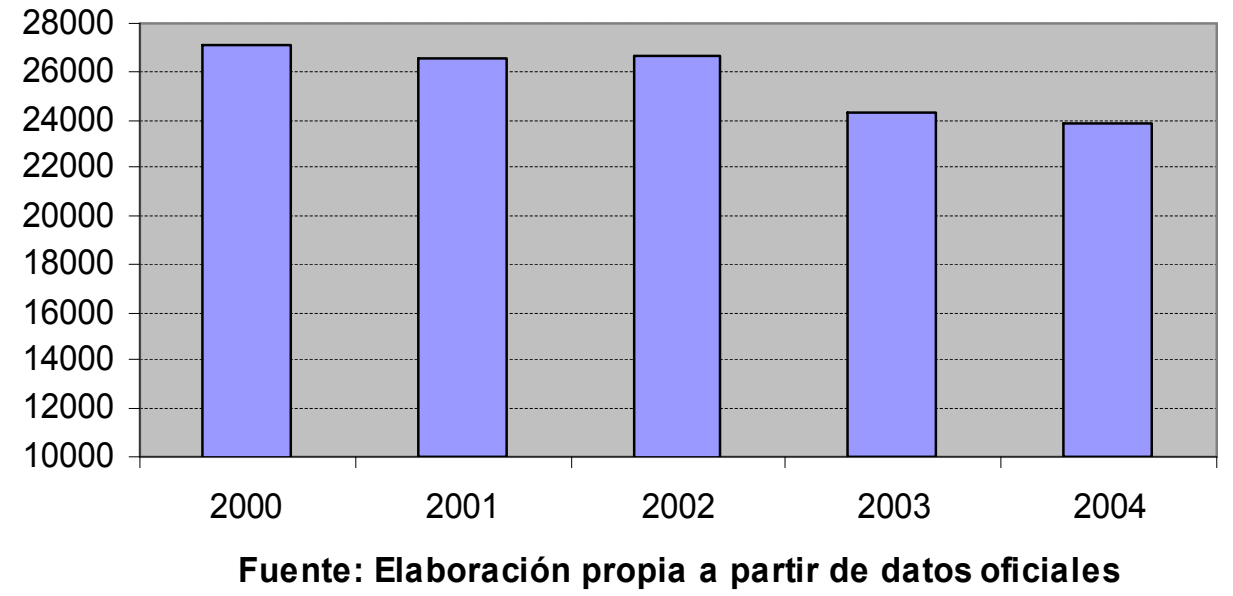

Si a continuación analizamos las clases de delitos que cometen los menores, observamos en el gráfico 17 que los delitos contra el patrimonio, y más en concreto los robos y hurtos, están sobrerrepresentados, incluso en mayor medida que en los adultos, de forma que el resto de infracciones delictivas tienen una presencia residual ${ }^{12}$.

\section{Gráfico 17.}

\section{Estructura de la criminalidad de los menores.} Delitos.

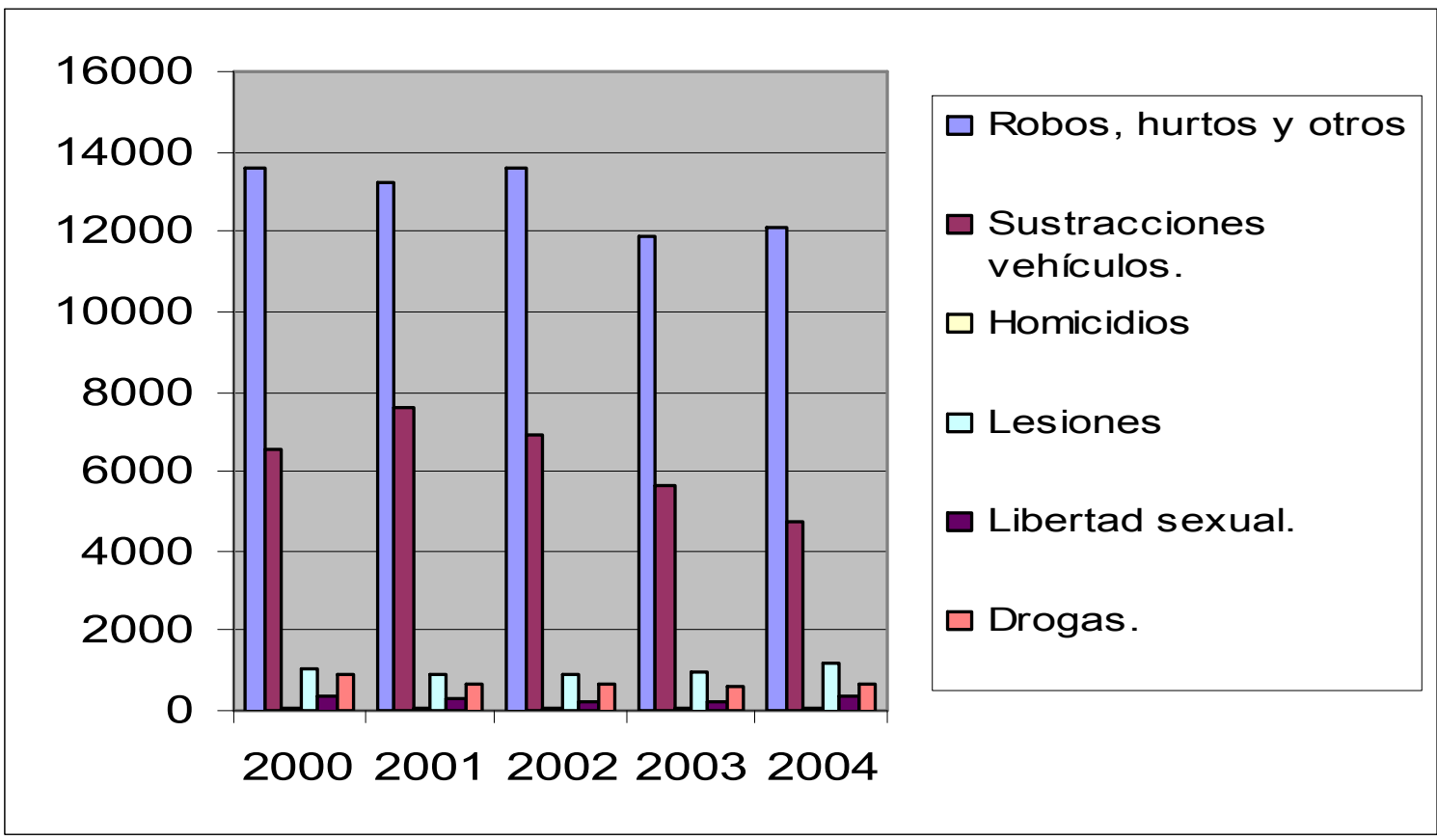

Fuente: Elaboración propia a partir de datos oficiales.

\footnotetext{
${ }^{12}$ Apréciese, por otro lado, que con el fin de lograr una visualización correcta, dada la gran frecuencia de comisión de estos delitos, he debido descomponer en dos columnas los delitos patrimoniales cometidos por menores, reservando la segunda solo para las sustracciones de y en vehículos.
}

Revista Española de Investigación Criminológica

Artículo 1, Número 4 (2006) http://www.criminologia.net 
El gráfico 18 confirma lo anterior centrándose en el número de homicidios y sus clases, consumados o intentados, realizados por menores de 18 años en los últimos cinco años: Se aprecian unas cifras estables, en torno a los 70 anuales, frente a una media de 1.450 en los adultos en ese mismo periodo.

\section{Gráfico 18.}

\section{Evolución de los homicidios realizados por menores.}

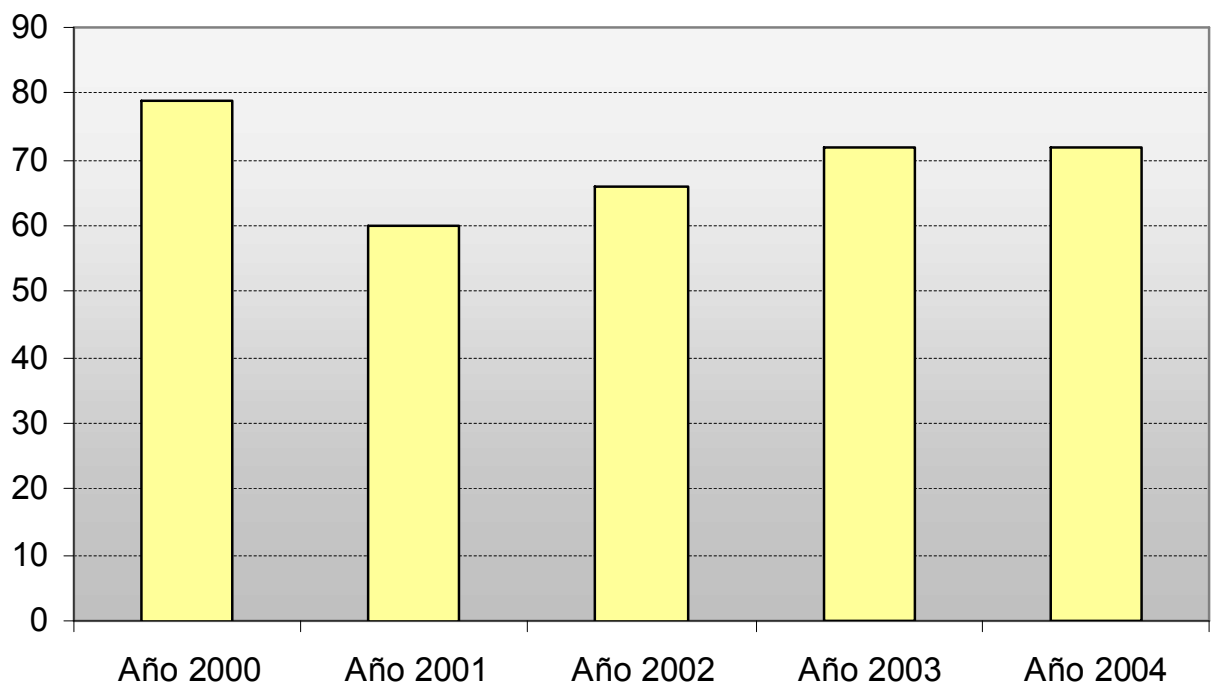

Fuente: Elaboración propia a partir de datos oficiales.

El gráfico 19 intenta descomponer la delincuencia de menores de acuerdo a las tipologías delictivas realizadas, pero diferenciando entre tres grandes grupos, los menores de 16 y 17 años, los de 14 y 15, y los que tienen una edad inferior a 14 años y que, como sabemos, no son responsables penalmente. Con estas diferenciaciones se pretende, en primer lugar, responder a las inquietudes recientemente surgidas sobre la frecuencia de actividad delictiva por parte de menores de 14 años, que no podría ser abordada con la ley de responsabilidad penal del menor, y, en segundo lugar, dar una explicación plausible, aunque parcial, al alegado incremento de la criminalidad de los menores en los últimos años.

\section{Gráfico 19.}

Relación edad/tipología delictiva en menores. 2004. 


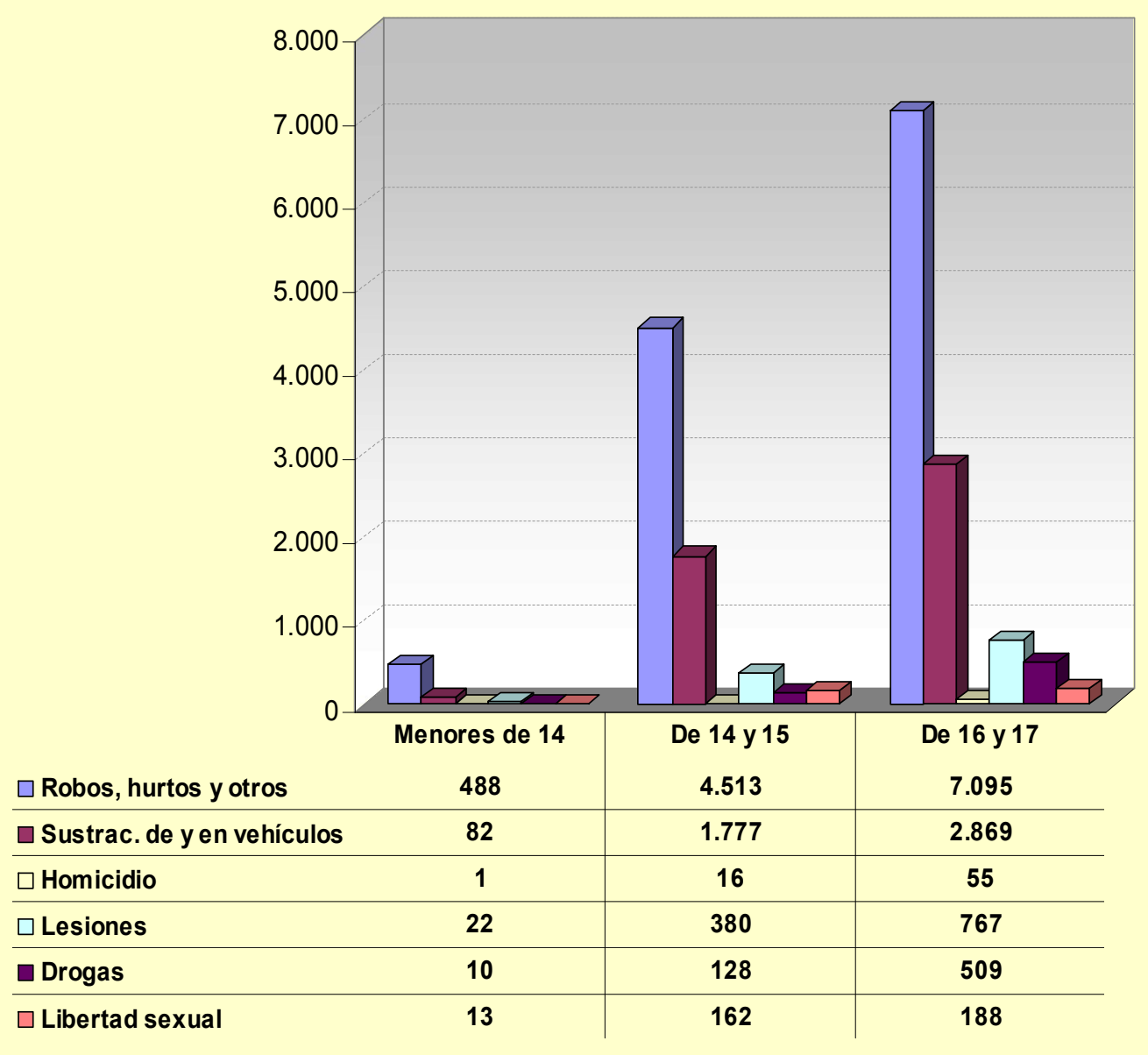

Fuente: Elaboración propia a partir de datos oficiales.

En efecto, podemos apreciar que el número y gravedad de las conductas delictivas realizadas por menores de 14 años son muy limitados, por lo que no estaría justificado un adelanto de la edad en la que los menores pueden ser responsables penalmente. Lo que procede es una mejora de las actuaciones en el ámbito de la protección de menores por debajo de los 14 años.

Igualmente, la preocupación por una mayor criminalidad de los menores no puede olvidar, como ya se ha puesto de manifiesto en otros estudios empíricos ${ }^{13}$, que la ley $5 / 2000$, de responsabilidad penal de los menores, incluyó bajo su ámbito a un tramo de edad, el de los 16 y 17 años, antes tratado conforme al derecho penal de los adultos y que constituye el grupo de menores con mayor prevalencia delictiva. Los datos acabados de suministrar apoyan esta explicación: Las cifras de delitos cometidos por el tramo de edad más alto casi siempre duplican e incluso triplican las cifras del tramo de edad precedente.

\section{EI control penal de los extranjeros en España.}

La determinación de la tasa de criminalidad de los extranjeros en España es una tarea ardua, que tropieza con importantes problemas metodológicos. En cualquier caso estudios criminológicos solventes aceptan que a partir de los insuficientes y poco matizados datos disponibles los valores resultantes se sitúan entre tres o cuatro veces

13 Véase por ejemplo García Pérez, O. "Estudio comparativo sobre la aplicación de las leyes de responsabilidad penal del menor 4/1992 y 5/2000. I". Boletín criminológico. nº 69. noviembre 2003.

Revista Española de Investigación Criminológica

Artículo 1, Número 4 (2006) http://www.criminologia.net 
por encima de los correspondientes a la población nacional, según se incluya o no a la población extranjera transeúnte ${ }^{14}$. Las deficientes condiciones económicas y sociales en las que se encuentra una buena parte de la inmigración irregular, su estructura de edad y sexo, y su lugar de residencia son algunos de los factores que darían razón en gran medida de este hecho.

Sin embargo, hay algunas referencias cuantitativas que son útiles para colocar en su debido contexto la criminalidad de los extranjeros. El gráfico 20 siguiente nos muestra que la evolución de las detenciones por infracción penal en España presenta en los dos últimos años un perfil muy semejante entre nacionales y extranjeros. Naturalmente, para poder realizar tal afirmación es necesario diferenciar entre los extranjeros detenidos por delito y aquellos que lo son por cometer una infracción administrativa, ligada por lo general a la situación irregular en la que se encuentran. Hecha esta distinción, se puede concluir que la evolución de la delincuencia de extranjeros, a juzgar por las detenciones que sufren, no muestra caracteres preocupantes aun constatando su tendencia general creciente ${ }^{15}$.

Gráfico 20.

\section{Evolución de detenciones de españoles/extranjeros.} 1997-2004.

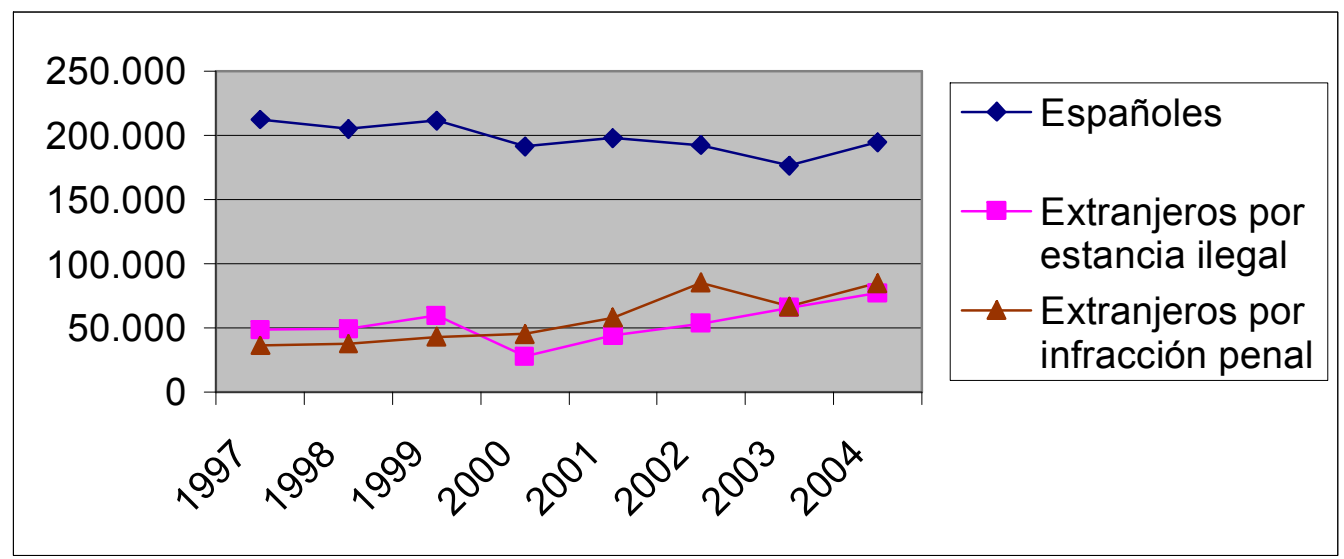

Fuente: Elaboración propia a partir de datos oficiales.

\footnotetext{
${ }^{14}$ García España. “Análisis cuantitativo de la delincuencia de inmigrantes”. Boletín criminológico. nº 49. septiembre-octubre 2000, con datos de 1997, estimó que los detenidos extranjeros por comisión de delitos o faltas se movían en una horquilla entre el 1,9 y el 2,7 por cada 100 extranjeros, correspondiendo el primer valor a los resultados obtenidos incluyendo la población transeúnte, y el segundo atendiendo únicamente a la población residente, regular o irregularmente; la tasa equivalente de la población nacional se encontraba en 0,55. A su vez García España y Pérez Jiménez. "Evolución de la delincuencia en España y Andalucía. Informe ODA 2004”, op.cit. págs. 61, 146-147, con datos del año 2003, y sin tener en cuenta la población extranjera transeúnte, calculan una tasa de detenidos extranjeros por delitos y faltas de 2,8 por cada 100 , mientras que la tasa nacional se encontraría en 0,56 . Véase asimismo una valoración de las importantes dificultades metodológicas para llegar a cálculos fiables, en Roldán Barbero. "Problemas metodológicos en la investigación de la delincuencia de inmigrantes", en "Inmigración y derechos de los extranjeros". Fdez. de Gal/G $\mathrm{G}^{\mathrm{a}}$ Cano drs. Publicaciones de la Universidad de Córdoba. 2005. págs. 203 y ss.

${ }^{15}$ Cabe añadir que en el gráfico recogido en texto se incluyen tanto detenciones por delito como por falta, lo que, dadas las condiciones establecidas por el art. 495 de la LECrim para proceder a detenciones por falta, implica necesariamente que se detenga en un porcentaje mucho más alto a extranjeros que a nacionales por la comisión de infracciones penales leves, lo que naturalmente afecta a las cifras absolutas de detenciones de aquellos.
}

Revista Española de Investigación Criminológica

Artículo 1, Número 4 (2006) http://www.criminologia.net 
Sin embargo, el uso de la prisión para abordar la delincuencia de extranjeros muestra una tendencia al alza desde hace una década, y se ha incrementado notablemente desde el año 2000, como se puede apreciar en el gráfico 21. Es pronto todavía para saber en qué medida la reforma que ha tenido lugar en el art. 89 del código penal en 2003, potenciando la expulsión de extranjeros como alternativa a la prisión, va a frenar ese incremento.

\section{Gráfico 21. Evolución porcentual de la población reclusa española y extranjera. Años 1996-2004.}

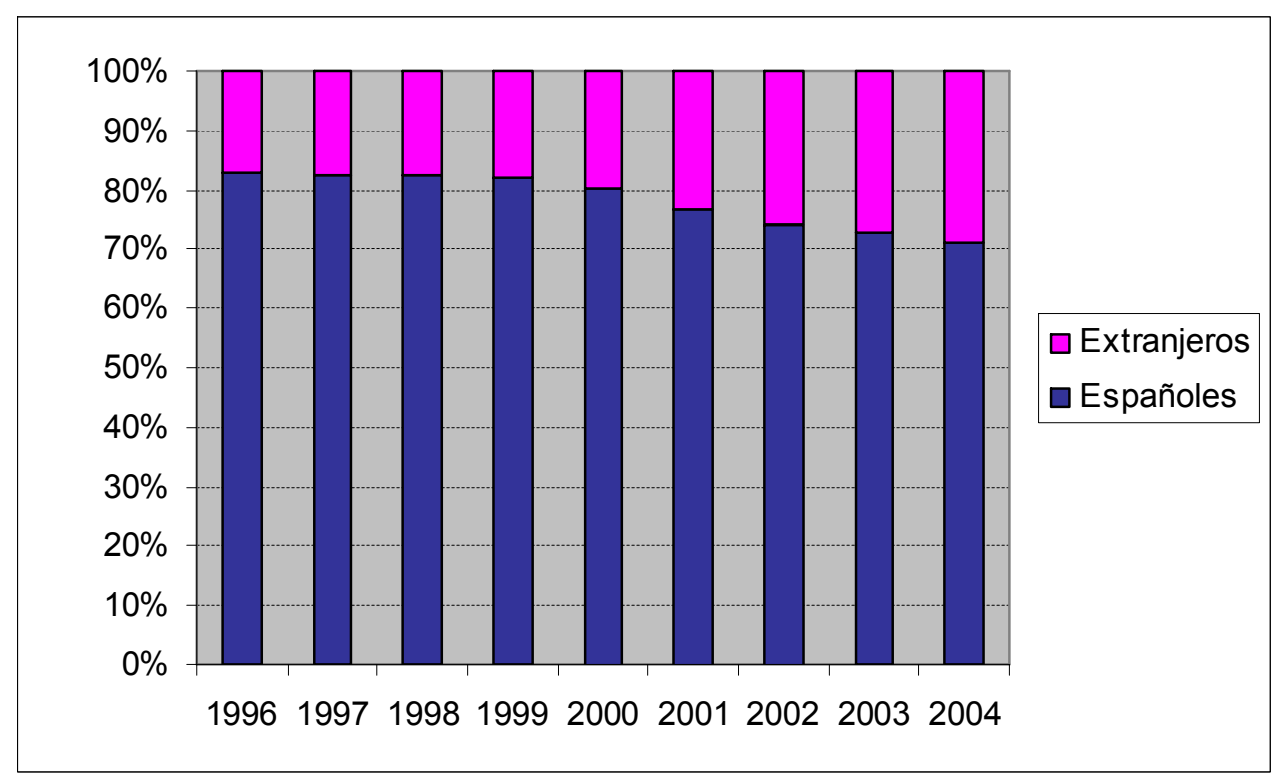

Fuente: Anuario estadístico del Ministerio del Interior. 2004.

Un dato, sin embargo, que da un margen de actuación en este tema es el resultante de la comparación de las cifras de población reclusa extranjera en los diferentes países del Consejo de Europa ${ }^{16}$. Naturalmente, dado el sentido de las migraciones, cabe esperar que los países de Europa occidental tengan unos porcentajes sustancialmente más altos que los de Europa oriental, y efectivamente así es. Sin embargo, la situación española, cuando ya se ha producido la aceleración del incremento de la población reclusa extranjera que acabamos de ver, es relativamente satisfactoria pues, pese a encontrarse por encima de la media de toda Europa, se localiza por debajo de los grandes países occidentales de la Unión europea, con la excepción de Francia, como destaca el gráfico 22.

\footnotetext{
${ }^{16}$ Véase Space I. Survey 2002. Council of Europe Penal Statistics. 2003.

Revista Española de Investigación Criminológica 


\section{Gráfico 22.}

\section{Tasa comparada de población reclusa extranjera. Año 2002.}

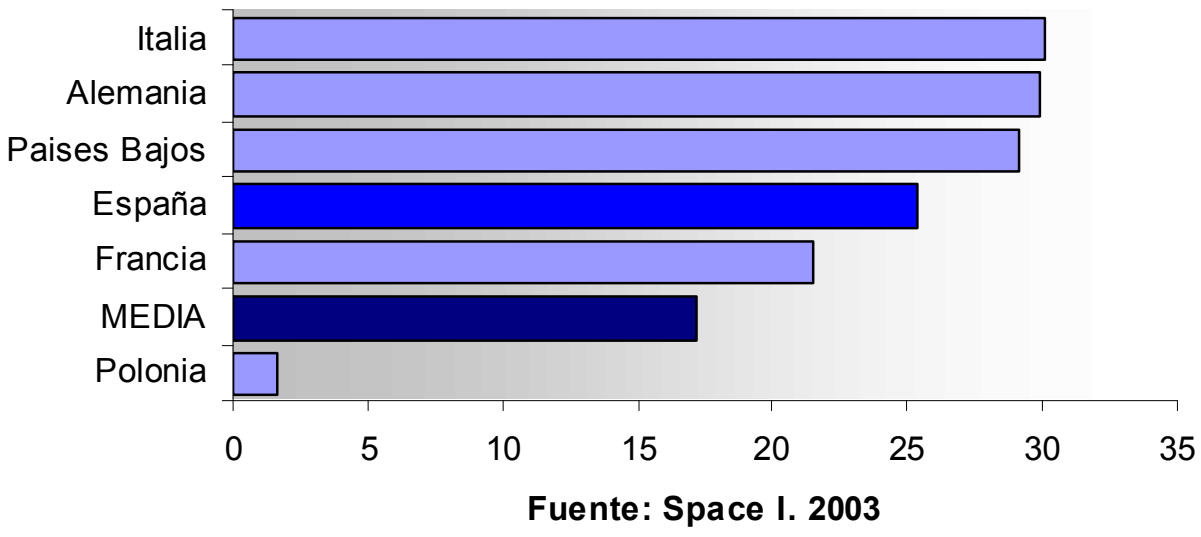

En suma, sin negar el origen extranjero de una parte de la criminalidad española, no se puede decir que su presencia sea determinante a la hora de explicar los actuales niveles de delincuencia españoles.

\section{Recapitulación.}

Los datos precedentes han puesto de relieve, en primer lugar, que nuestro país posee unas bajas tasas de criminalidad, en comparación con el conjunto de Europa y con los grandes países de la Unión europea. Sólo en relación con los delitos contra el patrimonio, singularmente robos con violencia e intimidación, presenta unos niveles claramente superiores a la media. En sentido contrario, llama la atención el reducido número de homicidios consumados.

La tasa de criminalidad española está experimentando un incremento moderado en la última década, aunque significativamente inferior a la que sufrió en los años 80 del pasado siglo. Por otra parte, el aumento está descansando de modo especial en las faltas, que tienen un fuerte ascenso, mientras que el incremento de los delitos es mucho más moderado y con frecuentes altibajos.

En cualquier caso se mantiene la estructura tradicional de la criminalidad española, en la cual los robos y hurtos dan cuenta de casi las $3 / 4$ partes de los comportamientos delictivos conocidos. Por lo demás, ni siquiera la reciente persecución intensa de los delitos de malos tratos es capaz de alterar la escasa representación que los delitos contra las personas han acostumbrado a tener en la delincuencia española.

Parece asimismo claro que la atención que los medios prestan en los últimos años a la criminalidad, y la preocupación que ésta suscita entre la ciudadanía, han crecido de manera desproporcionada, y no siempre de forma pareja, a la efectiva evolución de la delincuencia.

Es indudable que nuestro país abusa de la pena de prisión. Poseemos una de las tasas de encarcelamiento más altas entre los grandes países de la Unión europea, y nuestra población penitenciaria registra un fuerte crecimiento desde 1996, acrecentado a partir de 2001. Ese crecimiento no guarda relación con la evolución de la delincuencia, medida a partir de los hechos delictivos conocidos y del número de detenciones por comisión de delitos producidas. Ya hemos señalado en el apartado correspondiente 
cómo esa realidad es reflejo de una política criminal anquilosada en lo que se refiere al desarrollo del sistema de sanciones.

Tampoco responden tan altas cifras a una modificación en la composición de la población reclusa: Como ya es tradicional, más de $3 / 4$ partes de los penados están en la cárcel por la comisión de delitos contra el patrimonio o relativos a drogas.

La delincuencia grave de menores muestra en los últimos años una tendencia a la baja, a juzgar por el número de detenciones producidas. Por lo demás, todo lo que no sean hurtos y robos tiene una presencia residual en la criminalidad de los menores. No se aprecia una tendencia al incremento de los delitos contra las personas, como se ve en la estabilidad que muestran los homicidios intentados o consumados en el último quinquenio.

El tramo de edad más alto, los 16 y 17 años, concentra en gran medida la criminalidad juvenil, hasta el punto de que duplica o triplica, según los casos, las cifras del tramo inferior, 14 y 15 años. Los menores de 14 años, no incluidos en el derecho penal juvenil, apenas delinquen.

Con muchas cautelas puede afirmarse que los extranjeros muestran una tasa de criminalidad superior a la de los nacionales. Sin embargo, la evolución de las detenciones de extranjeros en los dos últimos años presenta una tendencia semejante a la concurrente en los españoles. Por el contrario, se aprecia un fuerte ascenso desde 2000 de su participación porcentual entre la población reclusa española, pese a que ese porcentaje sigue estando por debajo de casi todos los grandes países de Europa occidental.

A partir de este conjunto de datos creo que se puede concluir que la realidad delincuencial española no justifica el protagonismo adquirido por la inseguridad ciudadana en la agenda política y en la opinión pública de los años pasados, y que dio y sigue dando lugar a numerosas reformas de la legislación penal. El problema mayor que tiene en estos momentos la política criminal española es el anticuado sistema de reacción penal que emplea, y que ha dado lugar a unas tasas de encarcelamiento insostenibles. Allí deberían concentrarse los esfuerzos.

Más allá de esto, es urgente diseñar políticas sociales de integración de los extranjeros residentes, que permitan neutralizar las condiciones desfavorables que fomentan su aparentemente excesiva representación entre los delincuentes. Y no estaría mal que de una vez por todas nos preguntáramos qué peculiaridades concurren en nuestro país, o quizás en nuestras rutinas de persecución penal, para que, con independencia de las mejoras en nuestro desarrollo económico, la delincuencia patrimonial presente una frecuencia desconocida en otros países europeos. Por último, cuesta trabajo identificar, con los datos disponibles, la pretendida gravedad y frecuencia de la delincuencia de menores.

\section{Bibliografía.}

Council of Europe. 2003. "Space I. Survey 2002”. Council of Europe Penal Statistics. ---. 2004. "Space I. Survey 2003". Council of Europe Penal Statistics.

Domínguez Martínez y otros. 2000. "Estadísticas sobre la delincuencia en Andalucía". Instituto estadístico de Andalucía. Sevilla.

García España. 2000. "Análisis cuantitativo de la delincuencia de inmigrantes". Boletín criminológico. $\mathrm{n}^{\circ} 49$.

García España y Pérez Jiménez. 2004. "Evolución de la delincuencia en España y Andalucía: Análisis e interpretación de las estadísticas oficiales" (Informe ODA 
2004). Fundación El Monte-Instituto andaluz interuniversitario de Criminología. Málaga.

García España y Pérez Jiménez. 2005. "Seguridad ciudadana y actuaciones policiales" (Informe ODA 2005). Fundación El Monte-Instituto andaluz interuniversitario de Criminología. Málaga.

García Pérez, O. 2003. "Estudio comparativo sobre la aplicación de las leyes de responsabilidad penal del menor 4/1992 y 5/2000. I". Boletín criminológico. $\mathrm{n}^{\circ}$ 69. Málaga.

Home Office, BJu et al. "European Sourcebook of Crime and Criminal Justice Statistics". 2003. $2^{\text {nd }}$ edition. WODC.

Ministerio del Interior. 2004. "Anuario estadístico". www.mir.es/sites/mir/otros/publicaciones

Roldán Barbero. 2005. "Problemas metodológicos en la investigación de la delincuencia de inmigrantes", en "Inmigración y derechos de los extranjeros". Fdez. de $\mathrm{Gal} / \mathrm{G}^{\mathrm{a}}$ Cano drs. Publicaciones de la Universidad de Córdoba. Córdoba.

Soto Navarro. 2005. "La influencia de los medios en la percepción social de la delincuencia". RECPC. Granada.

Stangeland -García España -Márquez. 1994. "Discrepancias entre estadísticas policiales y judiciales”. Boletín criminológico. $\mathrm{n}^{\circ}$ 2. Málaga.

\section{EL AUTOR}

José Luis Díez Ripollés es catedrático de derecho penal de la Universidad de Málaga y director de la sección del Instituto Andaluz Inter-universitario de Criminología en dicha Universidad. Su labor investigadora está concentrada últimamente en la evolución de la política criminal española, la técnica y teoría de la legislación penal y aproximaciones empíricas a la delincuencia socioeconómica. 